\title{
Innovatively Saving the Future of Transportation: Small Aircraft Transportation System (SATS)
}

Jocelyn Nickerson, Brent Bowen, Russell Smith, and Scott Tarry

University of Nebraska at Omaha Aviation Institute

Massoum Moussavi

University of Nebraska-Lincoln

\begin{abstract}
The aviation industry is a rapidly changing entity of the world's economy. Millions of travelers consistently choose aviation as their mode of transportation because it is reliable, time-efficient, and safe. However, high demand has led to delays, cancellations, and gridlock. As the need for efficient travel options increases, passengers will look for other avenues of travel. Fortuitously, the National Aeronautics and Space Administration (NASA) and its partners are developing a unique and innovative alternative to this problem. The solution, known as the Small Aircraft Transportation System (SATS), will likely change the face of general aviation (GA) as it is known today. It is a clear concept, made credible by extensive research. The members of the Public Administration Department and the Aviation Institute of the University of Nebraska at Omaha have committed many of their resources to the successful realization of the SATS concept. These individuals have formed a unique Nebraska SATS research team, devoting their valuable time and effort to seeing the dream of SATS come true.
\end{abstract}




\section{Introduction}

The aviation industry, a rapidly changing entity of the world's economy, has allowed a variety of individuals to expand their businesses as well as their horizons through the use of commercial air carriers. However, the high demand for air travel has led to delays, cancellations, and gridlock. Yet the need for efficient options for business and personal travel is anticipated to increase steadily. Most travelers will soon experience the symptoms of an aviation industry seemingly overwhelmed by the traffic it so desperately needs to survive.

Contributing to the attitude that air travel is unsafe and inefficient is the fact that areas of transportation other than aviation are also plagued by traffic accidents and delays. Highways throughout the nation and the world are becoming increasingly ineffective in delivering travelers to their destinations in a timely manner. According to William Fay, president and CEO of the American Highway Users Alliance, "traffic congestion is growing, (which is) threatening safety, stifling production, slowing deliveries, and taking time from ... families" (2001).

Travelers have consistently chosen aviation as their mode of transportation because it is reliable, time-efficient, and safe. However, commercial airlines are required to follow routes that have been designated by the current hub-and-spoke system. This system emphasizes large airports and large aircraft and requires travelers to fly long distances through metropolitan areas to be advantageous. As these hubs become more and more crowded, passengers will look for other avenues of travel.

Perhaps consumers will look to the 5,000 small airports throughout the United States to alleviate their transportation problems. Unfortunately, these travelers will find that business strategies have not been created to address the air transport needs of rural and isolated communities. Even the Federal Aviation Administration (FAA) lacks the budget to deliver the efficiencies that the aviation industry demands. Without additional business to help maintain the facilities of these small airports, they will remain underutilized. The future of multifaceted air carriers looks bleak. An increase in safety and congestion problems has been predicted for both highways and runways. The decrease in client and customer satisfaction, coupled with a decrease in overall efficiency, will lead to loss of revenue, opportunities, and time. 


\section{Proposed Solutions}

Perhaps constructing new runways and introducing new airports is the answer to the aviation industry's crowding problems. Maybe larger aircraft to haul the increased traveling masses will provide the remedy. Increasing the cost of airline tickets could also dissuade passengers from using aviation. Twenty-four-hour airport operation and free flight could allow for additional flights on nondesignated paths. However, these solutions create new concerns.

Politics play a major role in the decision-making process. Thus, questions of environmental issues, noise problems, and funding associated with an increase in the number of runways and airports must be taken into account. The infrastructure, business plans, and organizational culture of individual airlines will determine whether changing aircraft size, ticket prices, and the number of flights is even feasible. Furthermore, travelers' preferences will likely influence what solutions, if any, are chosen.

\section{General Aviation as a Solution}

Perhaps increasing the current hub-and-spoke system is not the most appropriate solution. GA seems to be a viable environment to cultivate a new system of travel. In fact, for distances of 500 miles or less, GA flights are faster. This segment of the industry could fill the gap between customer satisfaction and what the airlines can provide. The needs of rural and isolated communities could finally be met by utilizing GA. The opportunity for expansion is available and necessary. Eighty-seven percent of small airports still lack systems that allow precision instrument approaches (ILS). With the use of such facilities, short-distance travel would become increasingly efficient.

Pioneering GA revitalization programs have been introduced and are already being developed and enhanced. The Advanced General Aviation Transport Experiment (AGATE) is a cost-sharing, industry-university-government alliance initiated by NASA. It was established to create the advanced technological basis that future GA flights will require. In addition, the General Aviation Propulsion (GAP) program was created to develop revolutionary propulsion systems (engines) for light aircraft.

Aviation manufacturers, such as Cirrus and Lancair, have already begun development of aircraft that will be technologically advanced enough to function effectively within the future GA environment. On-demand, point-to-point service will be available through jet aircraft with airlinerlike capabilities and coachlike fares. 
Japanese carmaker Toyota has also begun to establish its presence in the small airplane industry by producing an aircraft with the affordability and reliability of its high-end automobiles. Overall, those associated with aviation are becoming increasingly curious as to how GA can be utilized to save time and money.

However, there are a variety of questions surrounding the new developments that are being completed.

- Who will fly these technologically advanced aircraft?

- If congestion continues, how will travelers get to their destinations without delay?

- If highways become too inefficient, what method of travel will be used?

\section{Introducing a SATS}

NASA is developing a unique and innovative alternative to the current delay-driven transportation industry. This substitute for air carrier travel, SATS, will likely change the face of GA as it is known today. This system is considered to be a revolutionary concept in the provision of air transportation services.

SATS is defined as "an intermodal, personal, rapid transit, air travel system (with) the target consumer base (being) comprised of ... those consumers for whom the value of SATS transportation services can be economically or personally warranted" (Holmes 1999). This system will solve a variety of transportation problems while adding flexibility in air travel the likes of which the world has never seen.

Those who created this concept recognized the importance of time and remained sensitive to how long the execution of this system would take. Therefore, it was determined that SATS's goal would be to reduce public travel time by half in 10 years and two-thirds in 25 years. In addition, this would be completed at costs equivalent to those for the highway system, increasing mobility for all of the nation's communities through advanced on-demand air transportation. Those working on the development of this project have remained faithful to this time line and fully expect this goal to be accomplished.

\section{Instilling Public Confidence}

The aggression that our nation experienced on September 11, 2001, has changed the way many view the aviation industry. Few can travel without remembering the terrorist attacks. What has been so vividly displayed throughout the media has 
now become a distrust of transportation in general. Heightened concern for passenger safety must be addressed. The SATS system could provide the solution to the fear that many travelers are feeling.

Now more than ever, the original SATS technology strategy possesses the envisioned potential of providing a distributed safe travel alternative, freeing people and products from transportation system delays by creating access to more communities in less time. Now more than ever, the need for on-demand alternatives for travelers to move quickly and safely where they need to go, in the interest of national economic productivity, is paramount. SATS as originally envisioned, holds these promises. The challenge now to the government, industry and university partners is to focus sharply on the purpose and execution of the NASA program, that is, to prove SATS works (Holmes 2001).

SATS technologies were created to provide consumers with a safe alternative to crowded highways and airline hubs. The system employs small aircraft and underutilized airports to provide near all-weather access to more than 5,000 urban and suburban communities throughout the nation. This allows isolated communities to receive safe, affordable, and timely transportation.

What cannot be mistaken is the fact that SATS is no longer a futuristic concept. "NASA has completed the first year of developing the SATS requirements with the FAA, and has released the SATS Partnering Announcement. [This solicited] the formation ... of a nonprofit corporation as the public-private interface for the development of the FY 2005 SATS Demonstration" (Holmes 2001).

The United States will now demand "a transportation system that is robust, reliable, and resilient, in the face of any kind of disruption. Accessibility to air travel is fundamental to our nation's cherished freedom of movement" (Holmes 2001). SATS offers this kind of mobility while providing equal access to thousands of suburban, rural, and remote communities. "The SATS vision presents an alternative for preserving freedom of movement that can be developed with enhanced safety and security-based technologies" (Holmes 2001).

SATS utilizes larger numbers of smaller aircraft and airports. Reducing the concentration of travelers at large hubs would lead to fewer disruptions in travel and, therefore, greater robustness and resilience for the aviation industry. "Widely distributed systems in power grids, communication, computing, navigation systems, 
or in transportation are more robust ... than centralized systems. This theory of networks applies to the consequences of disruptions of any kind, such as caused by weather, labor disputes, system overload, or other causes" (Holmes 2001). In addition, a more effective domestic air support system would allow for more efficient "movements of people away from danger, movement for disaster relief, movement of law enforcement and other public service functions" (Holmes 2001).

Individuals as well as businesses will benefit from this system, which makes use of technologically advanced aircraft and systems. With more efficient and more effective equipment, SATS will provide air assistance to rural and isolated areas through point-to-point service between communities of all sizes. On-demand service will be based on travelers' specific needs in an effort to cater to the individual. This will provide an alternative for those communities that have been struggling with Essential Air Service. In addition to expanding service in communities already utilizing aviation, new air transport service will be offered to other remote communities. SATS will supply affordable, safe, reliable air travel while aiding in the revitalization of GA.

\section{Collective Efforts}

SATS is clearly a collaborative effort among a variety of distinguished individuals and institutions. Without each component of the SATS team, unarguably this concept would not come to fruition. Partnerships among the government, private firms, and universities have allowed the development of new technologies to begin. Private organizations have been charged with the creation of aircraft capable of using these technologies. Other private corporations must be committed to offering air transport services through the use of SATS aircraft and newly revitalized GA airports. In addition, the work of university-sponsored individuals will be required for a smooth transition in travel through SATS implementation.

\section{Nebraska SATS Research Team}

The Public Administration Department and the Aviation Institute of the University of Nebraska at Omaha (UNO) have committed many of their resources to the successful realization of the SATS concept. A number of individuals formed a unique Nebraska SATS research team and have devoted their valuable time and effort to seeing the dream of SATS come true. The initial activities of this team were divided into three subclusters and their corresponding support personnel. The subclusters were charged with investigating the areas of: 
1. systemic change and innovation in public infrastructure in Nebraska,

2. public finance and economics for SATS planning in the states, and

3. state and local airport planning for SATS implementation.

Dr. Russell Smith, Dr. Massoum Moussavi, and Mr. Fred Hansen were involved in subcluster 1 . Their research led them to investigate how the proposed small aircraft mode of transportation would be made more available throughout the nation's suburban, rural, and remote communities. They determined that the answers to this question would require research "in multiple policy, technological, market, and economic areas" (Bartle et al. 2000).

The systemic change and innovation subcluster focused on two areas. The first entails development of a formal systems engineering model for SATS implementation in the states, using Nebraska as an example. This systems engineering process could be used to develop a formal model for SATS. The formation of mathematical relationships would then be used to create a formal computer-based systems engineering model.

The second critical set of this cluster's activities focused on examining SATS as an innovation. The researchers were concerned with the important dimensions of the SATS technology, and how these dimensions might affect adoption of SATS by small airports in the United States (Bartle et al. 2000).

Nebraska will be used as an example to identify the unique qualities of SATS, such as capabilities, knowledge requirements, and cost. The projected rate of system adoption will be compared to the original roadmap goal. The difference between the two "would guide follow-on research activities in other project clusters" (Bartle et al. 2000).

Dr. John Bartle, Dr. David Hinton, and Richard Swayze, of UNO Public Administration, contributed to the second subcluster. They determined that federal development of SATS would require a series of national "templates." "These templates would serve as national guidance for state aviation system planning, regional intermodal transportation system planning, and airport master planning for [incorporation of] SATS technologies and capabilities" (Bartle et al. 2000).

In addition, the researchers found that the ultimate funding goal is to "match costs and benefits to the various affected parties" (Bartle et al. 2000). This ensures equity, plans for facility requirements, creates appropriate incentives, and stimulates 
technology. However, current federal financing tools are not capable of achieving these objectives. "The current grant and fee structure ... oversubsidizes certain airports and activities and undersubsidizes others" (Bartle et al. 2000). Such a customized approach requires the administrative capacity to weigh costs and benefits for each local project.

Therefore, the individuals working within this group were concerned with the financial and economic aspects relating to SATS. They "investigated the various financial options available to the federal government to build the SATS infrastructure in a manner that is both financially and administratively sustainable in the long term and is palatable to the states/local beneficiaries" (Bartle et al. 2000).

In addition, a general conceptual framework was developed for airport personnel to quantify both the direct and indirect benefits and costs to their various stakeholders. "This [framework] will develop the capacity on the part of federal and local officials to judge the propriety of projects, and to develop the necessary customized financial and administrative tools to implement them" (Bartle et al. 2000).

Researchers involved in the third subcluster included Dr. Hank Lehrer, Ms. Tracey Cullan, Mr. Fred Hansen, and Mr. Richard Swayze. This cluster's approach encompassed both short- and long-term goals for SATS. In the short term, it was determined that a statewide conceptual framework is crucial in developing the possible impact of the SATS airport program. "A need exists to justify the integration of SATS [technology] ... within the state airport master planning scheme" (Bartle et al. 2000). This comprehensive change will require significant coordination and evaluation.

Existing GA airports will play an integral part in the airport compliance strategy of SATS. However, before upgrades in systems and operations can take place, minimum airport standards for SATS facilities must be established. "These standards must be developed in partnership with the state and airport owners to define SATS capabilities tailored to current national and local requirements" (Bartle et al. 2000). Strategies must be developed to assist airports that are preparing for the introduction and use of SATS.

When considering the long-term aspects of this system, there is a need to develop airports that are capable of serving the rural populations of the United States. An example of this need is expressed in the distribution of population in the state of Nebraska. "Approximately 70 percent of Nebraska's population is concentrated within 50 miles of the Omaha/Lincoln area. This concentration of population ... 
has diminished the air service available to [other] residents of the state" (Bartle et al. 2000). While there are numerous airports in all portions of Nebraska, most of these airports have no air transportation other than widely scattered GA service. Utilizing a rural demonstration site in Nebraska with this demographic profile would validate the SATS concept and provide a template for future developments.

\section{Public Outreach and Education}

The importance of local and regional public outreach and education activities must not be underestimated. The implementation of SATS relies heavily on the participation of its stakeholders in such activities. Lack of public endorsement of the SATS concept will likely impede the realization of this program.

While it will be necessary for stakeholder groups to offer assistance, a specialized team of UNO representatives has been created to provide support through extensions of research activities. This SATS team "will provide an Internet-based forum for information dissemination and dialogue" (Bartle et al. 2000). An Internet platform has already been designed to accomplish this goal and can be viewed at www.unomaha.edu/ unoai/sats/. Additional tasks will include coordination with NASA Langley Research Center education personnel and links to stakeholders.

A SATS discussion board will also be available for posting related reports, papers, and other items. The team will coordinate with NASA's national public outreach and educational activities to provide support to the developing National Transportation Library. "Additionally, research outcomes will be brought into the collegiate classroom through courses such as airport master planning, operations, and independent research. Students will participate in course projects relating to SATS objectives" (Bartle et al. 2000).

\section{Nebraska Native American Outreach Program}

A large portion of Nebraska's Native American population has no access to public transportation of any kind. The development of an advanced airport system would bring air transportation access to a greatly underserved portion of the State as well as the region. A SATS facility "could form a vital link for isolated populations, providing enhanced access to health care, government, and employment opportunities" (Lehrer and Zendejas 2000).

However, this emergence will occur only through outreach and training within the associated school systems. The Nebraska Native American Outreach Program began five years ago as a partnership between the NASA Nebraska Space Grant Consortium (NSGC) and the Native American community, in response to the need for 
outreach activities. Through this program, "numerous ... projects have been undertaken, .. including educational, motivational, and infrastructure-building activities" (Lehrer and Zendejas 2000). In addition, this partnership has aided "the state's Native American educational community, particularly in the areas of improving mathematics, science, and technology" (Lehrer and Zendejas 2000).

"However, one clearly identifiable barrier in completing future projects ... is [the fact that] the Nebraska Native American population on [Nebraska's] reservations has been plagued by unemployment and extremely dismal family situations. As a result, school-age children often have difficulty in meeting minimum academic standards or even staying in school until graduation" (Lehrer and Zendejas 2001). The NSGC and Native American partnership was established to aid in the reversal of this trend.

\section{Annual NASA Aeronautics Day}

Another successful public outreach endeavor has been the annual NASA Aeronautics Day at the Sioux City (lowa) Airport. This program, begun in 1997, provides students attending Nebraska's reservation schools with experiences involving aeronautics and scientific aviation activities (Lehrer and Zendejas 2000). Seven hundred students have already become familiar with both military and general aviation operations. These projects have been extremely successful in highlighting aviation and aerospace as possible career options. It is anticipated that many of these youngsters will become fascinated with the thought of pursuing aviation careers and thus help to promote SATS in the future.

\section{Family Science Project}

The Family Science Project is designed to encourage families to work together to complete several hands-on activities. Such activities are taught during evening meetings at the students' schools. Occasionally, special demonstrations and guest speakers are included in the programs, which provide parents with ideas to encourage the completion of experiments and projects at home with their children.

"The purpose of this program is not to make parents into scientists or the primary teacher of their child, but to provide an opportunity for families to work together in an interesting and enjoyable manner" (Lehrer and Zendejas 2001). By doing such activities families can appreciate that science is not only for school but also for their real, everyday lives. "Doing such activities provides additional time for the learning of science and enhances student learning skills" (Lehrer and Zendejas 2001). 


\section{Systems Engineering}

The successful implementation of SATS will require the establishment of advanced technology at various airports. The SATS Systems Engineering Precursor Studies/ Nebraska Implementation was initiated to support the implementation of SATS in Nebraska. This research defines SATS and its requirements and provides a body of reference material for SATS implementation in Nebraska. The study supports the ongoing national SATS effort by developing a computer-based decision-support system/model for SATS implementation. The system's engineering requirements and SATS metrics for implementation in Nebraska are identified and their interrelationships (cause-and-effect relationships) are being investigated. These requirements and metrics include air travel demand, mobility, accessibility, travel time, travel cost, capacity, safety, vehicle technology, air traffic control, communications technology, airport facilities, demographics, and social, economic, political, and environmental factors.

Three alternative forms (verbal, visual, and mathematical) of the model are being developed. The verbal description is a mental model of the SATS system expressed in words. The visual description is diagrammatic and shows the cause-and-effect relationships between many variables in a simple and concise manner. The visual model, or "causal diagram," is being translated into a mathematical/computer model. The tentative framework for the SATS computer-based decision-support system/ model is based on the 23 submodels (demand forecasting, infrastructure planning, infrastructure design, regulatory and policy, market analysis, vehicle technology, air traffic control, pilot training, terminal area, airfield design, ground transportation access, safety, security, socioeconomics, environment, technology, politics, operations, administration, performance, implementation, organization, and public outreach). Initially, the SATS decision-support model is used to evaluate different scenarios of planning, design, and implementation of the small aircraft transportation system in Nebraska. The framework of the model is transferable to other states, and it is anticipated that an integrated form of the model will be developed at the regional and national levels in the future.

\section{Great Plains SATS Network}

On May 11-13, 2000, the Great Plains SATS 2000 Symposium was held in Rapid City, South Dakota. Representatives from 15 states participated in the program sessions and discussions, which focused on the issues surrounding SATS. Through this meeting it was determined that "the primary barriers to the implementation 
of SATS in the Great Plains will be market incentives rather than local infrastructure and financial limitations" (Smith 2000).

Symposium participants unanimously endorsed the implementation of SATS. In addition, each believed that the system could be used to address several chronic needs of the region, such as encouraging economic development, providing access to basic health and human services, and increasing support for existing and emerging airports (Smith 2000). Key issues that will demand the attention of SATS supporters were found "in areas of education and awareness, finance and economic development, infrastructure and planning, access and equity, and [governmental] roles" (Smith 2000).

\section{Issues Regarding Policy}

Three major policy areas were identified as having an impact on the implementation of SATS: public finance and economics, awareness and environmental factors, and diffusion of technology and technology transfer (Bartle et al. 1999).

Implementing SATS in Nebraska and in other states will require a number of technical and administrative changes. SATS will require major improvements in the infrastructure of state airports. However, supporters of SATS are faced with the dilemma of financing these improvements. The primary goal is to improve airport infrastructure so that it can accommodate SATS and remain financially self-sufficient with limited federal assistance (Bartle et al. 2000).

A variety of funding sources are available for the implementation of the SATS concept. Four major sources of revenues include:

1. federal grants,

2. debt financing,

3. earmarked taxes and user fees, and

4. innovative financing approaches.

The degree of use of any of these revenue options with SATS will depend largely on federal policy (Bartle et al. 2000).

Closely accompanying the financing options for SATS is the potential impact on local economic development. The goal of UNO's SATS researchers is "to develop a model that will allow for an assessment of the financial viability of the SATS investment at any airport. This will develop the capacity on the part of federal and local 
officials to judge the propriety of projects and to develop the necessary customized financial and administrative tools to implement them" (Bartle et al. 2000).

\section{Issues Surrounding Technological Transfer}

SATS represents a unique opportunity and fundamental effort to shift and diffuse technology throughout U.S. GA airports. However, many barriers to implementation are likely to exist. "Organizational change and the ability to accept new approaches to service delivery is a major hurdle for SATS implementation. To overcome this natural hesitancy, political support will have to be generated that outweighs the disincentives that exist" (Bartle et al. 2000).

Another barrier involves the financial resources required to modify and apply the technology appropriate to each GA facility. The differences between those developing the technology and those applying the technology must be considered. "The culture of organizations devoted to innovation and development is very different than the culture of general aviation airports and fixed-based operators who deliver services on a day-to-day basis" (Bartle et al. 2000).

Legal barriers, such as statutes and administrative procedures, must be addressed before successful implementation of SATS can take place. Each state and locality has distinct legal issues that will need to be reviewed to determine whether individual barriers exist. Then, appropriate steps must be taken to address those barriers properly. In addition, "education and training about SATS regarding how the technology works and how it can be applied successfully are key factors in implementation" (Bartle et al. 2000).

\section{Rural Policy Issues}

The airports most likely to be selected for SATS technology are those operated by rural and small communities. Many of these airports operate with part-time managers and staff with limited budgets. Traffic at these airports is usually local travel. "The larger of these airports receive the bulk of state infrastructure funding and support" (Bartle et al. 2000).

Thus, states with smaller, more rural populations and airports face serious capacity issues. In addition, "public attitudes toward taxing and spending have increasingly restricted government" (Bartle et al. 2000). The rapid change and increasing dependency of local economies has greatly reduced rural communities' control over their local economies. 
The implementation of SATS polices and its required technology depends heavily on the involvement of its supporters. Government officials must be committed to providing underserved communities with the resources they need to compete in the future aviation market. "The installation of advanced technologies and appropriate management systems throughout the nationwide network of general aviation airports can be delayed, slowed, and even halted at any one of many possible points at which a decision to commit resources must be taken" (Bartle et al. 2000). Consequently, a major component of the SATS planning phase must include a substantial effort to identify obstacles to implementation and the strategies for overcoming them.

The widescale adoption and implementation of SATS technology will require the review, modification, and creation of innovative public policies and management systems. "An analysis of current public policy and management frameworks that identifies gaps, as well as existing contradictory or countervailing policies that discourage innovation of new technologies, would be necessary to illuminate potential barriers to SATS adoption" (Bartle et al. 2000).

\section{Utilizing U.S. GA Airports}

According to the U.S. General Accounting Office's 1998 report, the United States has the largest, most extensive aviation system in the world (U.S. GAO 1998). This system ranges from large transportation centers to small grass landing strips. Of the 18,000 total U.S. airports, 3,344 smaller public-use airports are included in the national airport system. "Analysis shows that small airports have fewer flight operations, thus indicating that most general aviation airport use is by locally based aircraft rather than intercity travel" (Smith and Wachal 1999). These underutilized airports could provide a web of landing facilities for SATS operations to take place.

U.S. aviation operations have fallen off since the early 1980s. The "number of aircraft has declined by just under 20 percent," while the pilot base has declined by 11.9 percent (Smith and Wachal 1999). This reduction has been felt in Nebraska by a 15 percent decrease in its aircraft and a 23.3 percent decrease in its pilot base. Although the GA airport in Nebraska serves as a base for 14 aircraft, almost 25 percent base 4 or fewer aircraft (Smith and Wachal 1999).

SATS airports have certain basic technological requirements, which will be necessary to introduce to selected airports when implementation takes place. Nebraska's aviation industry is composed of basic utility airports, general utility airports, and jet transport airports with the following characteristics (Smith and Wachal 1999): 
- $77(85 \%)$ have a paved runway;

- 82 (90\%) have a lighted runway; and

- $56(65 \%)$ have an instrument approach.

However, current governmental plans for Nebraska airports do not include changes to support SATS. Rather, most state and federal funding is issued for repairs and maintenance. "The most recent comprehensive statewide airport planning effort in Nebraska (1992) recommended no infrastructure improvements for 27 (32.5\%) airports. Although some airports had low operations and based aircraft numbers, most appeared to have adequate infrastructure for their assigned aviation role (Smith and Wachal 1999). The implementation of SATS would require selected small Nebraskan airports to become equipped with new technology and new operating procedures. These changes may prove difficult especially when "more than one-third (30) of the GA airports do not have a primary runway that meets the recommended length and/or width for the airport" (Smith and Wachal 1999).

Nebraska facilities and airspace are available for increased operations. Such an increase would revitalize many small, underutilized airports and their surrounding communities. Nebraska aviation represents a fertile environment for the implementation of SATS technology and aircraft.

\section{Conclusions}

The implementation of SATS would be a dream come true for communities that urgently need air service and medical air transport. This system is a clear concept, made credible by extensive research. Although SATS is not an additional system for commercial airlines, it should not be thought of as a competitor. Rather, SATS should be viewed as a component of aviation that will help alleviate congestion at airline hubs to allow for increased customer satisfaction.

\section{SATS Advantages}

SATS will provide access to more communities in less time. This safe travel alternative will free both passengers and products from transportation system delays. SATS will better serve existing markets and extend air service to communities currently neglected by the airline industry. This will be accomplished through the use of advanced small aircraft, new innovations in navigation and communication technologies, and new business models. 
SATS offers a variety of benefits to the aviation industry as a whole as well as to the individuals who use the industry's services. The development of key airborne technologies and precision guidance of small aircraft create a safer and more efficient environment in which to fly. By occupying underutilized airports and airspace, SATS encourages less hub congestion and more rural travel. This is both an exciting opportunity and an economic development tool for those living in rural and isolated communities. High-speed mobility and accessibility will give travelers more time to complete their business.

In addition, SATS will likely reenergize the economies of the rural and isolated communities it serves. With fewer travelers frequenting highways and airline hubs, new innovations in intermodal travel will be required and thus created. New businesses will be needed, thus creating new jobs to facilitate the increase in traffic at small airports.

SATS has the potential to dramatically improve access to small and isolated communities while developing over 5,000 GA airports into operational business centers. New consumers and producers will be linked to the global economy rather than being confined to their immediately surrounding areas. Time is of the essence in the SATS endeavor. The opportunity to educate the public is upon us. When this phase of implementation is complete, travelers will be more knowledgeable about their transportation options, and able to actively participate in saving the future of transportation. 


\section{References}

Bartle, J., B. Bowen, G. Gogos, D. Hinton, B. Holmes, H. Lehrer, M. Moussavi, B. J. Reed, M. Schaaf, R. Smith, S. Vlasek, and S. Woods. 2000. NASA EPSCoR Nebraska Preparation Grant: Year 1. Omaha, NE: University of Nebraska at Omaha.

Bartle, J., B. Bowen, J. Deichert, H. Lehrer, D. Krane, B. J. Reed, and R. Smith. 1999. Policy implications for implementation of SATS at the state and local levels. Presentation at the National Academy of Sciences, August 17, Washington, DC.

Fay, W., and T. Cullan. 2001. American highway users alliance president calls for relief program to unclog nation's worst road bottlenecks. Insurance Advocate 112 (30):26-28.

Holmes, B. 1999. NASA aerospace enterprise national general aviation roadmap, small aircraft transportation system. Paper presented to National Research Council Workshop on the Public Sector Requirements for a Small Aircraft Transportation System, August 17, Washington, DC.

Holmes, B. 2001. Small aircraft transportation system program. NASA Langley General Aviation Program Office White Paper.

Lehrer, H. R., and E. Zendejas. 2000. NASA NE space grant/EPSCoR Native American outreach: Tracing a successful NASA/Tribal partnership. . Omaha, NE: University of Nebraska at Omaha Aviation Institute.

Lehrer, H. R., and E. Zendejas. 2001. Family aeronautical science: Improving math, science, and technology skills among Nebraska Native American children. University of Nebraska at Omaha Aviation Institute.

Smith, R. 2000. Great plains small aircraft transportation system (SATS) symposium communiqué.

Smith, R., and J. Wachal. 1999. General aviation in Nebraska: Nebraska SATS Project. Background Paper No. 1. Omaha, NE: University of Nebraska at Omaha.

U.S. General Accounting Office. 1998. Airport financing. Funding sources for airport development. RCED-98-71.

\section{About the Authors}

JOCELYN S. NICKERSON (jsnickerson@mail.unomaha.edu) is the research implementation and communications specialist for the University of Nebraska at Omaha Avia- 
tion Institute. She holds a bachelor's degree in aviation studies and a master of public administration degree, aviation concentration, from the University of $\mathrm{Ne}$ braska at Omaha. Mrs. Nickerson's responsibilities include implementation of funded research programs, grant report and proposal writing, development of applied research programs, and aeronautics and space education outreach. She is an FAA-licensed and instrument-rated private pilot.

MASsoum Moussavi (moussavi@unomaha.edu) is an associate professor of civil engineering at the University of Nebraska-Lincoln. He received his B.S. degree from West Virginia Institute of Technology and his M.S. and Ph.D. degrees from Virginia Polytechnic Institute and State University. He has 17 years of experience in teaching, research, and consulting in transportation engineering. Dr. Moussavi is a member of several professional organizations, and he is registered professional engineer in Nebraska and Tennessee.

BRENT D. BOWEN (bowen@unomaha.edu) is the Regent's Distinguished Professor of Aviation and serves as director for the Aviation Institute and as director of the Division of Air Transportation Policy at the University of Nebraska at Omaha. In addition, Dr. Bowen is the program director and principal investigator for the $\mathrm{Na}$ tional Aeronautics and Space Administration funded by the Nebraska Space Grant Consortium and NASA EPSCOR Program. He is an airline transport-rated pilot and serves as an aviation safety counselor for the FAA.

RusSELL L. SMITH (rlsmith@mail.unomaha.edu) has been a public administration faculty member and director of the Center for Public Affairs Research at University of Nebraska at Omaha since 1986. He has published articles addressing state and local government management issues in a variety of journals. Dr. Smith served as a member of the editorial board for Review of Public Personnel Administration (19791984) and as coeditor of the Journal of the Community Development Society (19921995).

SCOTT E. TARRY (starry@unomaha.edu) is associate professor of aviation and public administration for the Aviation Institute at the University of Nebraska at Omaha. He is program vice-president elect of the Transportation Research Forum, a member of the Executive Committee of the American Society for Public Administration's Section on Transportation Policy and Administration, and an active participant in the Air Transport Research Society. His work on aviation has been published in several journals. He is currently studying the impact of a SATS on air transportation and economic development in rural and isolated communities. 